\title{
Carbon Based Nanomaterials
}

\author{
Nida Tabassum Khan* and Muhammad Jibran Khan \\ Department of Biotechnology, Faculty of Life Sciences and Informatics, Balochistan University of Information Technology Engineering and \\ Management Sciences, Quetta, Pakistan
}

*Corresponding author: Nida Tabassum Khan, Department of Biotechnology, Faculty of Life Sciences and Informatics, Balochistan University of Information Technology Engineering and Management Sciences, (BUITEMS), Quetta, Pakistan

\begin{abstract}
With the dynamic new advances and techniques, we were likewise acquainted with more up to date types of carbon, for example, graphene quantum dots, graphene oxide, fullerenes, and carbon-based nanotubes. In the realm of nanotechnology, particularly, carbon nanomaterials have been a forward leap; from tranquilize liberation to synthetics, carbon's allotropes have demonstrated to be harder than steel and more productive than some other material.
\end{abstract}

Keywords: Graphene oxide; Carbon nanotubes; Fullerene; Biosensing; Photoluminescence; Robustness

\section{Introduction}

In the field of science and innovation, carbon-based nanomaterials are turning out to be alluring nanomaterials [1]. Because of the presence of various allotropes of carbon, from famous allotropic stages, for example, undefined carbon, graphite and precious stones to newfound favorable carbon nanotubes (CNTs), graphene oxide (GO), graphene quantum dots (GQDs) and fullerene, carbon-based materials have as of late become prized [2-4]. Each member from the carbon family shows supreme features and has been commonly employed in various normal applications including biosensing, metabolites transport, tissue building, imaging etc. [5,6]. Among all, SWCNT (single walled carbon nanotube) and MWCNT (multi walled carbon nanotube) are quite popular [7]. SWCNTs, with a round and empty nanostructure, are made by climbing a lone graphitic sheet with a high viewpoint extent [8]. On the other hand, MWCNTs contain very few graphitic layers with an interlayer separation of 3.4Angstrom [9]. Because of its exceptional mechanical, electrical and fundamental conventional assortment, it strengthens common, flexibility and electrical conductivity toward various natural components, which is useful for recognizing, clinical findings [10]. In any case, among the various allotropes of carbon, graphene is seen as the most charming material owing to its exceptional natural properties [11]. Around 70 years back, in 1947, Wallace surveyed the electronic structure of graphene $[12,13]$. Over the span of the latest two decades, research on graphene has massively extended, and diverse phenomenal properties have been seen [14]. Another carbon member is GQDs, which is defined as a zero-dimensional graphene sheet with an equal component of under $100 \mathrm{~nm}$ in one to a few layers [15]. GQDs possess great photoluminescence in view of quantum confinement [16]. Additionally, GQDs pass on sharp features of graphene, for instance, an immense surface zone and available p electrons, which make the GQDs an insightful nanomaterial for a wide extent of biomedical applications, including imaging, coordinated movement, biomolecules identifying, and so forth $[17,18]$.

\section{Carbon Nanotubes Biomedical Applications}

Inferable from their astounding essential, mechanical, electronic, and optical properties, CNTs have been seen as another age nanoprobes [19]. Their high conductivity, engineered robustness, affectability and speedy electron-move rate make them exceedingly fit for biosensing applications such as CNTbased biosensors and optical biosensors [20,21]. CNTs have been celebrated as promising materials for improving electron move, 
which makes them appropriate for joining electrochemical and electronic biosensors [22,23].

\section{Examples:}

a. Numerous CNT-glucose biosensors reliant on the affixation of glucose oxidase have been constructed [24]. it utilizes carbon nanotube non-woven surfaces (CNTFs) to identify glucose from a glucose oxidase-impregnated polyvinyl alcohol plan [25].

b. In another study, glucose oxidase shrouded MWCNT is used in electrochemical glucose detection [26].

c. Electrochemical biosensors dependent on CNTs have been proposed for distinguishing nitric oxide and identifying epinephrine [27].

d. Besides, 20 specific SWCNT crown stages for distinguishing human blood proteins were developed [28]. The examination revealed that the specific crown stage was fit for identifying fibrinogen with increased selectivity [29].

\section{Graphene Oxide for Biomedical Use}

e. Graphene have been comprehensively used for identification of single and twofold stranded DNA [30]. This high affectability is due to the unique ionic correspondence between the nucleobases, and the graphene carbon structure $[31,32]$ which enables the detection of the four bases of DNA [33].

\section{Examples:}

f. A significantly consistent and returnable graphenebismuth composite device was designed for detecting glucose molecule [34].

\section{Graphene Quantum Dots for Biomedical Application}

g. GQD-based biosensors have been made for medical examination and contaminants discovery [35].

Examples:

h. Based on splendid photoluminescence and electrochemiluminescence property of GQD, they have been employed in distinguishing biological macromolecules including DNA, with improved selectivity [36,37].

i. Another GQD based biosensor namely GQD- $\mathrm{Zr} 4 \mathrm{C}$ phosphorylated peptide conjugate was able to identify casein kinase II protein [38].

j. Similarly, pyrene-1-boronic functionalized GQD for glucose identification [39].

k. Structured Pd NPs completed N-doped GQD (NGQD) for cancer revelation [40].

l. Graphene quantum dots having an oxygen-rich surface renders it suitable for stacking drug particles [41]. The drug stacked nanoconjugate exhibited improved tissue penetration and cellular uptake which empowers major implementation both in vitro and in vivo [42].

\section{Toxicity of Carbon Nanomaterials}

Carbon nanomaterials are a novel class of materials that are commonly used in biomedical fields but they still suffer from their noxious effects on natural structures [43]. The effect of metal staining impacts in CNT could generously influence destructiveness [44]. Additionally, long CNT incited extraordinary inflammation, which caused dynamic fibrosis [45]. Inquisitively, surface functionalization of CNT initiated harmfulness in cells such as- $\mathrm{COOH}$ functionalized SWCNT impelled higher noxiousness appeared differently in relation to the non-functionalized SWCNT in the HUVEC cell lines [46]. Graphene has in like manner limitations to biomedical application in light of its hurtfulness [47].

\section{Conclusion}

Thus, carbon-based nanomaterials have numerous applications and has potential scope in the future.

\section{Reference}

1. Gogotsi Y, Presser V (2013) Carbon nanomaterials. CRC press pp. 529.

2. Coville NJ, Mhlanga SD, Nxumalo EN, Shaikjee A (2011) A review of shaped carbon nanomaterials. South African Journal of Science 107(34): 1-15.

3. Jariwala D, Sangwan VK, Lauhon LJ, Marks TJ, Hersam MC (2013) Carbon nanomaterials for electronics optoelectronics photovoltaics and sensing. Chemical Society Reviews 42(7): 2824-2860.

4. Hong G, Diao S, Antaris AL, Dai H (2015) Carbon nanomaterials for biological imaging and nanomedicinal therapy. Chemical reviews 115(19): 10816-10906.

5. Zhang M, Naik RR, Dai L (2015) Carbon nanomaterials for biomedical applications. Springer (5).

6. Cui X, Xu S, Wang X, Chen C (2018) The nano-bio interaction and biomedical applications of carbon nanomaterials. Carbon 138: 436-450.

7. Dresselhaus MS, Dresselhaus G, Eklund PC, Rao AM (2000) Carbon nanotubes. In The physics of fullerene-based and fullerene-related materials. Springer Dordrecht pp. 331-379.

8. Niyogi S, Hamon MA, Hu H, Zhao B, Bhowmik P et al. (2002) Chemistry of single-walled carbon nanotubes. Accounts of Chemical Research 35(12): 1105-1113.

9. Fischer JE (2006) Carbon nanotubes: structure and properties. Nanotubes and nanofibers 1(1).

10. Arnold MS, Green AA, Hulvat JF, Stupp SI, Hersam MC (2006) Sorting carbon nanotubes by electronic structure using density differentiation. Nature nanotechnology 1(1): 60-65.

11. Pumera M (2010) Graphene-based nanomaterials and their electrochemistry. Chemical Society Reviews 39(11): 4146-4157.

12. Varchon F, Mallet P, Veuillen JY, Magaud L (2008) Ripples in epitaxial graphene on the Si-terminated SiC (0001) surface. Physical Review B 77(23): 235412.

13. Lambin P (2003) Electronic structure of carbon nanotubes. Comptes Rendus Physique 4(9): 1009-1019.

14. Ahmad A, Lokhat D, Rafatullah M (2019) Survey of graphene-based nanotechnologies. In Graphene-Based Nanotechnologies for Energy and Environment Elsevier pp. 23-39. 
15. Bacon M, Bradley SJ, Nann T (2014) Graphene quantum dots. Particle \& Particle Systems Characterization 31(4): 415-428.

16. Zheng XT, Ananthanarayanan A, Luo KQ, Chen P (2015) Glowing graphene quantum dots and carbon dots: properties, syntheses, and biological applications. Small 11(14): 1620-1636.

17. Shen J, Zhu Y, Yang X, Li C (2012) Graphene quantum dots: emergent nanolights for bioimaging, sensors, catalysis and photovoltaic devices. Chemical communications 48(31): 3686-3699.

18. Zhang L, Xing Y, He N, Zhang Y, Lu Z (2012) Preparation of graphene quantum dots for bioimaging application. Journal of nanoscience and nanotechnology 12(3): 2924-2928.

19. Yang W, Thordarson P, Gooding JJ, Ringer SP, Braet F (2007) Carbon nanotubes for biological and biomedical applications. Nanotechnology 18(41): 412001 .

20. Sinha N, Yeow JW (2005) Carbon nanotubes for biomedical applications IEEE transactions on nano bioscience 4(2): 180-195.

21. Beg S, Rizwan M, Sheikh AM, Hasnain MS, Anwer K (2011) Advancement in carbon nanotubes: basics, biomedical applications and toxicity. Journal of pharmacy and pharmacology 63(2): 141-163.

22. Bianco A, Kostarelos K, Partidos CD, Prato M (2005) Biomedical applications of functionalized carbon nanotubes. Chemical Communications, (5): 571-577.

23. Vardharajula S, Ali S Z, Tiwari PM, Eroğlu E, Vig K (2012) Functionalized carbon nanotubes: biomedical applications. International journal of nanomedicine 7: 5361-5374

24. Zhu Z, Garcia Gancedo L, Flewitt A J, Xie H, Moussy F (2012) A critical review of glucose biosensors based on carbon nanomaterials: carbon nanotubes and graphene. Sensors 12(5): 5996-6022.

25. Liu Y, Wang M, Zhao F, Xu Z, Dong S (2005) The direct electron transfer of glucose oxidase and glucose biosensor based on carbon nanotubes/ chitosan matrix. Biosensors and Bioelectronics 21(6): 984-988.

26. Wang SG, Zhang Q, Wang R, Yoon SF, Ahn J (2003) Multi-walled carbon nanotubes for the immobilization of enzyme in glucose biosensors. Electrochemistry Communications 5(9): 800-803.

27. Jacobs CB, Peairs MJ, Venton BJ (2010) Carbon nanotube based electrochemical sensors for biomolecules. Analytica chimica acta 662(2): 105-127.

28. Kimmel DW, LeBlanc G, Meschievitz ME, Cliffel DE (2012) Electrochemical sensors and biosensors. Analytical chemistry 84(2): 685-707.

29. Zhang Y, Lim CT, Ramakrishna S, Huang ZM (2005) Recent development of polymer nanofibers for biomedical and biotechnological applications. Journal of Materials Science: Materials in Medicine 16(10): 933-946.

30. Luo M, Chen X, Zhou G, Xiang X, Chen L (2012) Chemiluminescence biosensors for DNA detection using graphene oxide and a horseradish peroxidase mimicking DNAZYME. Chemical Communications 48(8): 1126-1128

31. Li B, Pan G, Avent ND, Lowry RB, Madgett TE (2015) Graphene electrode modified with electrochemically reduced graphene oxide for label-free DNA detection. Biosensors and Bioelectronics 72: 313-319.
32. Gao L, Lian C, Zhou Y, Yan L, Li Q (2014) Graphene oxide-DNA based sensors. Biosensors and Bioelectronics 60: 22-29.

33. Liu F, Choi JY, Seo TS (2010) Graphene oxide arrays for detecting specific DNA hybridization by fluorescence resonance energy transfer. Biosensors and Bioelectronics 25(10): 2361-2365.

34. Mani V, Devasenathipathy R, Chen SM, Subramani B, Govindasamy $M$ (2015) A novel glucose biosensor at glucose oxidase immobilized graphene and bismuth nanocomposite film modified electrode. Int J Electrochem Sci 10(1): 691-700.

35. Wang Z, Zeng H, Sun L (2015) Graphene quantum dots: versatile photoluminescence for energy, biomedical, and environmental applications. Journal of Materials Chemistry C 3(6): 1157-1165.

36. Qian ZS, Shan XY, Chai LJ, Ma JJ, Chen JR et al. (2014) DNA nanosensor based on biocompatible graphene quantum dots and carbon nanotubes. Biosensors and Bioelectronics 60: 64-70.

37. Benítez Martínez S, Valcárcel M (2015) Graphene quantum dots in analytical science. TrAC Trends in Analytical Chemistry 72: 93-113.

38. Wang Y, Zhang L, Liang RP, Bai JM, Qiu JD (2013) Using graphene quantum dots as photoluminescent probes for protein kinase sensing. Analytical chemistry 85(19): 9148-9155.

39. Maiti D, Tong X, Mou X, Yang K (2019) Carbon-based nanomaterials for biomedical applications: a recent study. Frontiers in pharmacology 9: 1401.

40. Maduraiveeran G, Sasidharan M, Ganesan V (2018) Electrochemical sensor and biosensor platforms based on advanced nanomaterials for biological and biomedical applications. Biosensors and Bioelectronics 103: $113-129$.

41. Chen Y, Chu M (2017) Graphene Quantum Dots for Drug Delivery. World Scientific Encyclopedia of Nanomedicine and Bioengineering Ii, The: Bioimplants, Regenerative Medicine and Nano-cancer Diagnosis and Phototherapy 3(9).

42. Schroeder KL, Goreham RV, Nann T (2016) Graphene quantum dots for theragnostic and bioimaging. Pharmaceutical research 33(10): 2337 2357.

43. Chen M, Zhou S, Zhu Y, Sun Y, Zeng G (2018) Toxicity of carbon nanomaterials to plants, animals and microbes: Recent progress from 2015-present. Chemosphere 206: 255-264.

44. Liu Y, Zhao Y, Sun B, Chen C (2013) Understanding the toxicity of carbon nanotubes. Accounts of chemical research 46(3): 702-713.

45. Magrez A, Kasas S, Salicio V, Pasquier N, Seo JW, (2006) Cellular toxicity of carbon-based nanomaterials. Nano letters, 6(6): 1121-1125.

46. Gutiérrez Praena D, Pichardo S, Sánchez E, Grilo A, Cameán AM et al. (2011) Influence of carboxylic acid functionalization on the cytotoxic effects induced by single wall carbon nanotubes on human endothelial cells (HUVEC). Toxicology in Vitro 25(8): 1883-1888.

47. Yang K, Li Y, Tan X, Peng R, Liu Z (2013) Behavior and toxicity of graphene and its functionalized derivatives in biological systems. Small 9(9-10): 1492-1503. 
(C) (1) This work is licensed under Creative

To Submit Your Article Click Here: $\quad$ Submit Article

DOI: $10.32474 /$ LOJMS.2020.05.000214

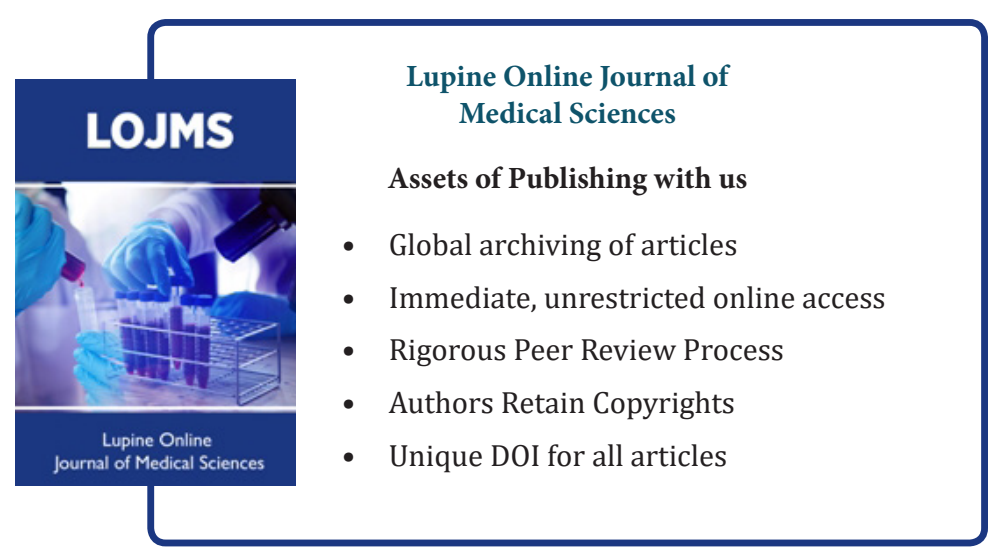

